\title{
Need for Shift from Hypothesis to Data Driven Approach in Fisheries Research- An Opinion Paper
}

\author{
Shivakumar $\mathbf{M}^{*}$ \\ Professor of Aquatic Biology, College of Fisheries, India \\ *Corresponding author: Shivakumar Magada, Professor of Aquatic Biology, College of Fisheries, India

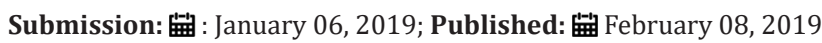

\begin{abstract}
Science is not changing every day, but our understanding. Through systematic research based on hypothesis, scientists give a lead towards possible truth. With more and more such hypothesis, we can go nearer to the truth. In all fields of research, it is customary to design research based on hypothesis. Scientists test their hypothesis using suitable test statistics and arrive at some conclusion. But the technical, economic feasibility and replicability of such results will decide the rate of its adoptability. The results of sample survey, hypothesis-based research may go wrong in many instances. Intricacies between parameters in a dynamic aquatic system are so complex. This leads us to conclude the results with certain assumptions and conditions. These conditions and assumptions limit the translation of knowledge into reality. When dealing with system level research, developing and under developed countries cannot afford to waste time and money on hypothesis. Due to the advancement information technology, huge data can be collected, processed which enabled better understanding of correlations between parameters and results can be predicted with precisely. If the research shifts from hypothesis to data driven approach, most of the results can directly applied in the intended field. The results of Data Driven Approach in Research (DDAR) will play vital role in designing developmental programs and policy making. DDAR also attracts funding support from industries and more technology will move to the field.
\end{abstract}

Keywords: Hypothesis; Data driven approach; Fisheries research; Big data

\section{Introduction}

About 2500 years ago there was a glorious awakening. Greek philosophers argued that the universe is knowable. Why? Their reasoning: It is ordered. At about $600 \mathrm{BC}$ we meet the pioneers of science. Mysticism began to become obsolete. The world could be explained with the help of what they called logos. They began to wonder how the nature is built. They figured out that the base for all understanding of nature is the question: "What is reality? "Some believed that all reality has a mental origin. This led to the concept of idealism. A hypothesis is a suggested solution for an unexplained occurrence that does not fit into current accepted scientific theory. The basic idea of a hypothesis is that there is no pre-determined outcome. For a hypothesis to be termed a scientific hypothesis, it has to be something that can be supported or refuted through carefully crafted experimentation or observation. This is called falsifiability and testability, according to the Encyclopaedia Britannica. A key function in this step in the scientific method is deriving predictions from the hypotheses about the results of future experiments, and then performing those experiments to see whether they support the predictions. Any useful hypothesis will enable predictions by reasoning (including deductive reasoning). It might predict the outcome of an experiment in a laboratory setting or the observation of a phenomenon in nature. The prediction may also invoke statistics and only talk about probabilities. Karl Popper, following others, has argued that a hypothesis must be falsifiable, and that one cannot regard a proposition or theory as scientific if it does not admit the possibility of being shown false. Other philosophers of science have rejected the criterion of falsifiability or supplemented it with other criteria, such as verifiability (e.g. verificationism) or coherence (e.g. confirmation holism). The scientific method involves experimentation, to test the ability of some hypothesis to adequately answer the question under investigation. In contrast, unfettered observation is not as likely to raise unexplained issues or open questions in science, as would the formulation of a crucial experiment to test the hypothesis. A thought experiment might also be used to test the hypothesis as well.

In framing a hypothesis, the investigator must not currently know the outcome of a test or that it remains reasonably under continuing investigation. Only in such cases does the experiment, test or study potentially increase the probability of showing the 
truth of a hypothesis. If the researcher already knows the outcome, it counts as a "consequence" -and the researcher should have already considered this while formulating the hypothesis. If one cannot assess the predictions by observation or by experience, the hypothesis needs to be tested by others providing observations. For example, a new technology or theory might make the necessary experiments feasible. People refer to a trial solution to a problem as a hypothesis, often called an "educated guess" because it provides a suggested solution based on the evidence. However, some scientists reject the term "educated guess" as incorrect. Experimenters may test and reject several hypotheses before solving the problem.

According to Schick and Vaughn, researchers weighing up alternative hypotheses may take into consideration:

a) Testability (compare falsifiability as discussed above).

b) Parsimony (as in the application of "Occam's razor", discouraging the postulation of excessive numbers of entities).

c) Scope-the apparent application of the hypothesis to multiple cases of phenomena.

d) Fruitfulness-the prospect that a hypothesis may explain further phenomena in the future.

e) Conservatism-the degree of "fit" with existing recognized knowledge-systems.

In spite of being a poor country, India had, since its independence in 1947, devoted scarce resources to the development of a science and technology infrastructure and a high-quality system of higher technical education [1]. The government dominated research and development activity. Over $80 \%$ of the $R \& D$ done in India was financed by the government of India and conducted within government research laboratories [2]. India is spending $0.8 \%$ of National Net Product on science research as against 2.5 in China, 2.7 in Sweden 3-4 in USA. Most of the leading Universities in world receive funding support of industries. In 1980 itself, India became the strongest scientific and technology centre among developing countries, but little benefit is occurring to the industry. With a few exceptions, the public sector failed to drive the Indian fisheries sector on to a higher growth trajectory and got bogged down by cost and time overruns, high costs, and a lack of technological dynamism [3]. Farmers and industrialists started borrowing technologies directly from the developed countries. The shrimp hatchery, farming, feed and processing technologies are all from other countries. Research in fisheries sector in India and the fisheries industry are moving independently on their own pace. Amount spending on research and their output is just meagre. In spite of having All India Coordinated Research Projects (AICRP) program, there is duplication of research in agriculture fields [4]. But, only few such AICRP on post-harvest is there for fisheries. There are 800-900 fisheries scientists in the country which worked to be one scientist for every 17.5 lakh people by taking 135 crores of present population. The chance of increasing this number is meagre but all these numbers have to join together and form core research group and take up the projects and each one of them can work in their specialization leading to achieve the broader goal.

Like in banking systems, there must be mechanism to identify the duplication. Many leading institutes claim that they developed the breeding technology for scampi and gold fish while they were produced in millions by farmers for many years. The data available in the Department of Fisheries on details of the tanks, ponds and reservoirs are taken from Irrigation Department or the Department of Revenue. These data are not revised for decades [5]. Thousands of minor and major tanks have changed significantly in terms area, depth, water retention period, weed infestation, encroachment, bund breaching etc. And in urban areas, some tanks are converted into layouts. Many are not fit for fisheries development; but still they find a place in the records. In India, except for few reservoirs, there is no mechanism for collection of catch data. The catch data for Indian fisheries still goes with 'Estimation' and fisheries in the most part of the country is managed based on their own understanding which mostly copied by the other farmers Somehow Something Fisheries Technology (SSFT).

Looking at the data on food habit of Indians, Government institutions need not take up researches on raw meat eating, fish sauce, caviar processing, salmon farming. More than $99 \%$ of the hypothesis-based researches, researcher will accept alternative hypothesis. More often scientists are afraid to accept null hypothesis. Because, accepting null hypothesis does not support their career. But water quality monitoring experiments funded by industries at least in India will accept the null hypothesis. Because, you are paid to accept null hypothesis. Environment related projects should not be taken up under the funding support of industries. Before the conduct of experiments, experimenter is sure of accepting either null or alternative hypothesis will lead to pile up of unnecessary data. Will knowing that results will follow such trends and since the jurisdiction of science is entire world, most of the duplication of research can be avoided. We have accepted the radio, aeroplane, telephone, cancer medicine discovered by someone, somewhere and be used by the entire world. Likewise, the technology developed in any part of the world can be borrowed, purchased at cheaper cost. We don't try to invent the Indian versions. However, continuous research is required to improve the efficiency.

\section{Case Report I}

In case of sea bass, cobia, pompano and mud crab breeding, Indian research institutes have invested more than 500 crores over a period of three decades. On the other hand, all these species are bred on commercial scale in Taiwan, Vietnam etc. Certified seeds of those species can be imported. This works out to be cheaper. Our aquaculture system has accepted exotic species, feed, medicine, technicians and equipment's, why not these seeds. While importing seed, there will be risk of exotic pathogens. Hundreds of foreign technicians were here in India to establish black tiger shrimp hatcheries. Similar way, a big team of expert scientists from other countries can be employed and our scientists can work with them. 
Wherever, governments cannot invest huge amount of money, private sector can be involved and supported. The success of Penaeus monodon, P. indicus and L. Vannamei in India is not directly attributed to research outputs of research institutes. Entrepreneurs brought the technology directly from Japan, United States and other Asian countries. The wonder drug "Ovaprim" -the hormone used in induced breeding of fishes is imported from Canada. However Indian institutes popularized the concepts.

\section{Case Report II}

Potential Fishing Zone Advisories-it is yet another hypothesis driven concept. Based on sea surface temperature and chlorophyll, satellite capture pictures. It is correlated to abundance of pelagic fishes. In a qualitative survey, $90 \%$ of the fishermen (120) in Malpe and Mangalore region of Karnataka, India are not happy and do not rely on PFZ advisories. Even fisheries department officials endorse their opinion. But still funding agency claims that it has reduced the income by reducing CPUE. Regional institutes validate the PFZ advisories with funding support of main agency and end up appreciating their claims. Project continues and fishermen continue to do in their own way.

\section{Case Report III}

\section{Breeding of Air Breathing Catfishes and other Fish Species}

There were claims in early 70s that air breathing catfishes were bred in captivity. Still we are unable to have an established network. Records are there to claims that breeding technologies are available for Notapterus chitala, Clarias Batrachus, Channa spp. Ompak bimaculatus, L. Gonius, L. Calbasu, L. Bata, Puntius sarana, P. Jerdoni, P. Gonionotus, Heteropneustes fossilis, Pangasius pangasius, Horabaghrus brachysoma etc. But there is no data on area cover under each species and their production as it is done in agriculture whenever they develop a new variety.

\section{Case IV}

Virtually freshwater prawn farming is scanty in India. Carp fish products are not available in Indian market except stray quantity in North Eastern states. Some research group worked on value chain in carps and prawn and spends to a tune of 3.0 crores on research. Simply by knowing production and consumption data, the same amount would have been invested on the right issues that are bothering the sector.

\section{Case V}

\section{Cage farming}

It is an age-old practice in many countries like Norway, Hawai etc. Its success directly depends on suitable site, species, cost of production and consumer preference. It is just a capital-intensive business venture. For open sea cages, if the safety standards demand certain quality, no point in designing low cost cages at the cost of safety. If the Indian technologies are not competitive enough for taking up these activities, we can directly import the technologies. Without sufficient backup for seed, feed, organizations have set a big goal and struggling to achieve it. Hence, since four decades, cage farming continues to be potential sector in India. However, with continuous efforts of ICAR institutes and developmental departments, low cost cage farming is picking up in the country. Successfully, cages farming has been taken up in freshwater bodies. Now, it's time to work more on economic feasibilities. These failures are repeatedly occurring because we have fixed ourselves for hypothesis driven research. If we do not change our approach from hypothesis to DDAR, we cannot meet the projected demand for fish forever.

\section{Data Driven Approach in Research (DDAR)}

It is new approach emerged out of information technology revolution. India is harnessing the technology and trying to build strong data base. The government is providing Open Government Data Platform (OGD) India is a single-point of access to Datasets/Apps in open format published by Ministries/ Departments. But, checks and measures to be taken at data collection point. Any data collected systematically will not go waste. While collecting it might look it is useless; but it will become treasure after few years. With all India networks of researchers, we must carefully select the researchable issues and take up mission mode research program. For example for sea bass, the entire team right from cage, installation, feed, breeding, marketing, cold chain and value added products, the team must work for sufficiently long time. This can be taken up in collaboration with private participation. All the available data has to be updated after ground truthing. It might cost big money, but the advantages and usefulness in the future is unfathomable. There must be separate team to identify the right gaps and researchable issues and recommend the institutes to work on the proposed issues in collaboration with the beneficiaries. To shift from hypothesis to data, immediately the country needs up gradation of the following data:

a) Demography

b) Farmers database

c) Catch data

d) Waterbodies: Area, type, nature, number

e) Area under aquaculture

f) Production constraints

g) Species cover v/s area

h) Production and productivity

i) Cost of production in different systems

j) Consumption pattern against price, species, season, product

k) Shift in preferences

I) Seed and feed requirement 
m) Adoption rate of technology

n) Training needs

o) Bottlenecks in the policies, schemes and initiatives

p) Market intelligence and survey

q) All the schemes and initiatives of the developmental departments.

While appreciating all the efforts of the present and earlier scientists in India who have done commendable job, this paper is written to draw attention of present scientific community to choose the right research programs (issue and need based) and help the farming community with a strong empirical data which can be reproducible. Otherwise technology package will not move out of academia and farmers will go on their own. While formulating the research program, the critical thinkers and progressive farmers, industrialists and economists have to be included in the committee. This brings transparency and accountability among both the sides. India has all the solutions for the problems that we are facing now. We need more translators of knowledge into reality and agents of change. It is happening now and you be a catalyst.

\section{References}

1. Krishnan RT. The Evolution of a developing country innovation system during economic liberalization: The case of India.

2. Forbes N (1999) Technology and Indian industry: What is Liberalization Changing? Technovation 19: 403-412.

3. Ørsted HC (1811) First introduction to general physics. 18. Selected scientific works of Ørsted HC, p. 297.

4. Feynman R (1965) The character of physical law. p. 156.

5. Theodore S, Lewis V (2002) How to think about weird things: Critical thinking for a new age. McGraw-Hill Higher Education, Boston, Massachusetts, USA.

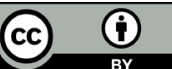

Creative Commons Attribution 4.0 International License

For possible submissions Click Here

\section{Submit Article}

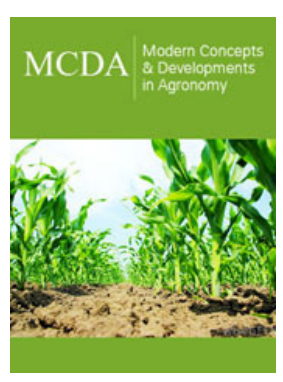

Modern Concepts \& Developments in Agronomy

\section{Benefits of Publishing with us}

- High-level peer review and editorial services

- Freely accessible online immediately upon publication

- Authors retain the copyright to their work

- Licensing it under a Creative Commons license

- Visibility through different online platforms 